\title{
Coronary Artery Bypass Graft Surgery in a Rare Case of Coronary Artery Anomaly - Single Coronary Artery Originating from the Right Aortic Sinus
}

\author{
Anshuman Darbari, Devender Singh ${ }^{1}$, Anish Gupta, Barun Kumar ${ }^{2}$ \\ Departments of CTVS and ${ }^{2}$ Cardiology, AllMS, Rishikesh, Uttarakhand, 'Department of CTVS, Kovai Medical Center and Hospital, Coimbatore, Tamil Nadu, India \\ ORCID: \\ Anshuman Darbari: https://orcid.org/0000-0002-4524-2359 \\ Devender Singh: https://orcid.org/0000-0002-2951-0114 \\ Anish Gupta: https://orcid.org/0000-0002-4704-6271 \\ Barun Kumar: https://orcid.org/0000-0002-2562-1714
}

\section{Abstract}

Single coronary artery (SCA) is a very rare congenital anomaly, in which the entire coronary system arises from the solitary ostium with the incidence of $0.024 \%-0.066 \%$ in the general population undergoing coronary angiography. It is usually considered a benign entity but may cause chest pain, hemodynamic abnormalities, myocardial ischemia, or sudden cardiac death owing to its course arising between the pulmonary artery and aorta. The diagnosis of congenital coronary artery anomalies is usually made by conventional coronary angiography and very few cases have been reported in the literature. To the best of our knowledge, we report this as a first case, in which successful off-pump coronary artery bypass grafting was done for a SCA system.

Keywords: Coronary anomalies, coronary artery disease, off-pump bypass surgery

\section{INTRODUCTION}

Congenital coronary anomalies are found in $0.2 \%-1.3 \%$ of patients undergoing coronary angiography and they are further defined as any unusual pattern in origin, course or termination. In these anomalies, subset of single coronary artery (SCA) is found in approximately $0.066 \%$ of the population. This anomaly has been reported in association with and without atherosclerotic changes or in association with other congenital pathologies. Coronary arterial anomalies vary widely in clinical significance and presentations, so treatment and management is still not standardized.

\section{Case Report}

A 63-year-old male patient presented to the cardiology department with chief complaints of left-sided chest pain off

Received: 14-10-2019 Revised: 25-11-2019 Accepted: 02-12-2019

Published Online: 11-06-2020

\begin{tabular}{|l|l|}
\hline \multicolumn{3}{c|}{ Access this article online } \\
\hline Quick Response Code: & Website: \\
& \\
&
\end{tabular}

and on exertion suggestive of angina for $1 \frac{1}{2}$ years without any dyspnea. He was a chronic smoker and occasional alcoholic for 5 years. During the initial evaluation and workup at our hospital, his electrocardiograph was unremarkable and echocardiography was suggestive of normal left ventricular function with no regional wall motion abnormality. The physical examination and laboratory data were normal. His conventional coronary angiography (CAG) was done because of the persistent history of chest pain. We found that the entire coronary system as a common trunk arose from the single ostium and suggested an anomalous origin of the left main stem from the right Ostia, with very long main crossing the right ventricular outflow tract, left anterior descending (LAD) arose

Address for correspondence: Dr. Anshuman Darbari, Department of CTVS, AlIMS, Rishikesh - 249 203, Uttarakhand, India. E-mail: darbarianshu@gmail.com

This is an open access journal, and articles are distributed under the terms of the Creative Commons Attribution-NonCommercial-ShareAlike 4.0 License, which allows others to remix, tweak, and build upon the work non-commercially, as long as appropriate credit is given and the new creations are licensed under the identical terms.

For reprints contact: WKHLRPMedknow_reprints@wolterskluwer.com

How to cite this article: Darbari A, Singh D, Gupta A, Kumar B. Coronary artery bypass graft surgery in a rare case of coronary artery anomaly - Single coronary artery originating from the right aortic sinus. Int $\mathrm{J}$ Cardiovasc Acad 2020;6:86-8. 


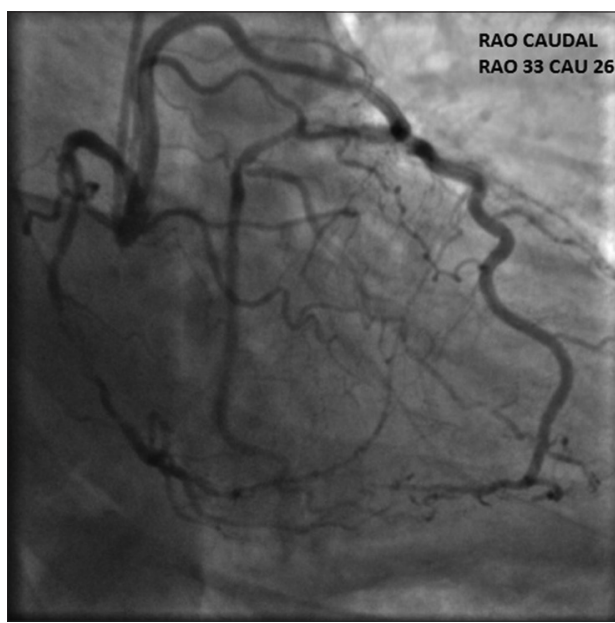

Figure 1: Coronary angiogram (right anterior oblique caudal view) showing a single coronary ostium arising from the right coronary sinus of Valsalva. The ostium gives rise to a common trunk that courses along the right ventricular free wall and constitutes the right coronary artery, which, in turn, expands to the left ventricular free wall and joins the left circumflex coronary artery. An acute branch arises from the proximal common trunk and it forms the LAD coronary artery, which travels in the interventricular groove

from the left main stem, and had moderate-to-severe disease in the proximal LAD artery. The left circumflex artery also arose from the left main stem and had moderate-to-severe disease in the proximal artery [Figure 1]. The right coronary artery (RCA) had severe disease from the mid vessels to the distal vessels. He was posted for off-pump coronary artery bypass grafting. After opening pericardium, purse-string sutures were taken on the aorta and right atrium appendage for possible need of cardiopulmonary bypass in case of hemodynamic instability. Operative findings were suggestive of healthy LAD, but obtuse marginal (OM) OM-1, OM-2, and posterior descending artery (PDA) were diffusely diseased [Figure 2]. Off-pump on beating heart left internal mammary artery (LIMA) to LAD grafting was done under controlled local suction stabilization of the myocardium. After it, reverse saphenous vein grafts to the PDA, OM-1, and OM-2 on the distal side and proximally to the aorta were done [Figure 3]. Intraoperatively, no hemodynamic event occurred. Postoperative recovery was smooth, and the patient was discharged after 8 days of uneventful hospital stay.

\section{Discussion}

In a large series of 126,595 patients undergoing $\mathrm{CAG}$, a single coronary artery (SCA) from the right sinus of Valsalva was found in $0.019 \%$. About $40 \%$ of SCA anomaly cases are associated with congenital heart diseases such as Fallot tetralogy, transposition of great arteries, persistent truncus arteriosus, and pulmonary atresia.

Initially, the classification of SCA is made by Lipton. Later, modified Lipton classification included features such as the anatomical distribution, the ostial location, and the course of the transverse trunk. Ogden in 1970 classified "SCA" into

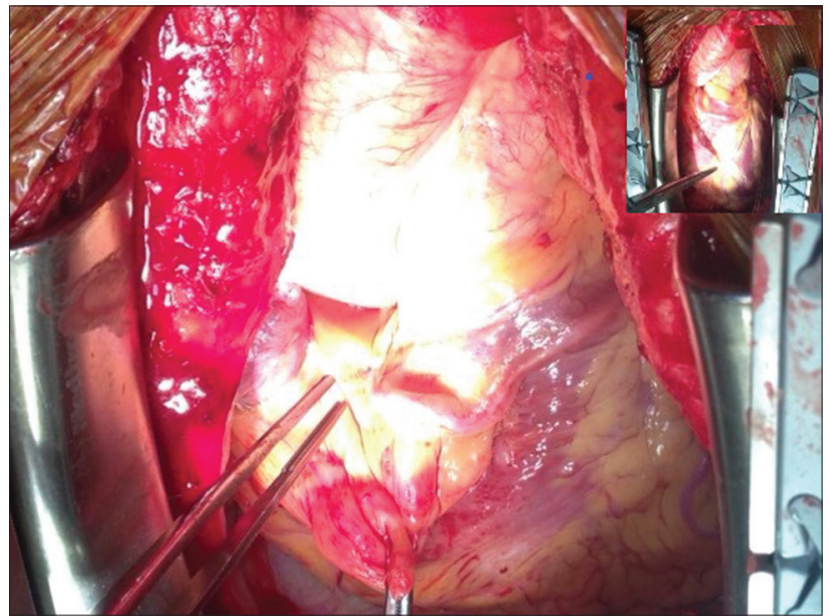

Figure 2: Intraoperative photograph showing a common trunk of single coronary artery arising from the right coronary sinus. Inset picture showing the left anterior descending coronary artery (pointed by forceps tip) after giving the right coronary artery branch

14 basic distribution patterns. Later, Shirani and Roberts classified a SCA into 20 categories based on the location of the solitary coronary ostium and the presence or absence of an aberrant coronary artery and the course taken by the aberrant-coursing coronary artery.

In this type of SCA, the entire coronary tree arises as a common trunk from the right coronary sinus dividing into the RCA, which has a normal course and the left main coronary artery (LMCA). Then, the LMCA crosses the base of the heart turning anteriorly the aorta and dividing it into LAD and circumflex arteries. In the malignant or interarterial type of this anomaly when LMCA crosses between the aorta and pulmonary artery, patients might present with sudden death due to the compression and kinking of LMCA, especially during physical exertion. The SCA anomaly is usually asymptomatic but may present as myocardial ischemia, syncope, or sudden cardiac death (SCD) depending on its course and the presence and severity of atherosclerosis. Myocardial ischemia or SCD is usually associated with its course between the aorta and the main pulmonary artery or posterior variant. ${ }^{[1]}$ Yet, there is not an established treatment strategy guide for a SCA. The course of these anomalous coronary arteries and association with atherosclerotic disease determine the treatment strategy. ${ }^{[2]}$

\section{Terminology}

In 2005, Rigatelli et al. based his classification on clinical significance of the anomaly and launched a global practical classification of four categories (Class A: benign; Class B: relevant due to fixed myocardial ischemia; Class $\mathrm{C}$ : severe, involved in SCD; and Class D: critical due to worsened clinical picture).$^{[3]}$ Due to the risk of sudden death in patients whose anomalous coronary artery courses between the aorta and pulmonary artery, coronary artery bypass surgery is useful even if patients have not severe atherosclerotic coronary stenosis. Symptomatic carriers have three treatment options: 


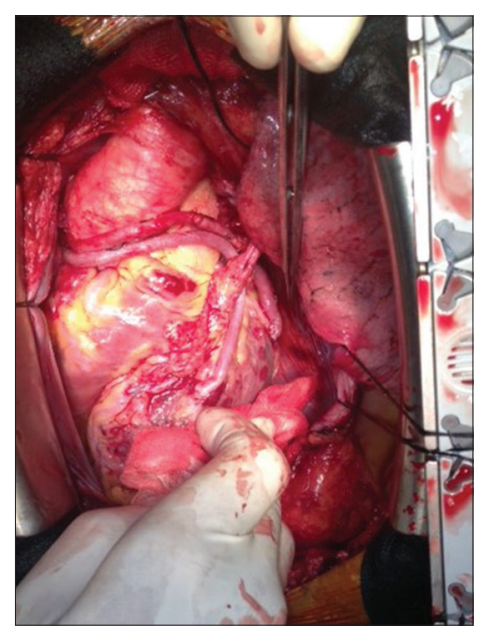

Figure 3: Intraoperative photograph at completion showing bypass grafting of the left internal mammary artery to the left anterior descending (pointed by fingertip) and reverse saphenous vein grafts to obtuse marginal- 1 (pointed by forceps tip) and obtuse marginal-2 (pointed by fingertip) on distal aspects and proximally to the aorta. The left lung is also seen in the picture

medical treatment/observation, coronary angioplasty with stent deployment, and surgical repair. Despite the limitations of our current knowledge of such anomalies, intervention may be justified in selected cases to prevent sudden death and improve the quality of life. ${ }^{[4,5]}$ Surgical strategy involves the replacement of the anomalous coronary artery to the coronary sinus appropriately or bypass surgery as in our case.

\section{ConcLusion}

The determination of the anomalous origin of the coronary artery is of great clinical importance due to its severe life-threatening complications. The new imaging modalities such as multislice computed tomography and cardiovascular magnetic resonance imaging have also emerged to enable the accurate visualization of the anatomical configurations and the detection of this structural malformation. Both these tests in addition of conventional CAG have the additional advantage of three-dimensional reconstruction of the areas of the coronaries relative to the aorta and pulmonary artery and a definitive diagnosis of squeezed aberrant coronary arteries between these great vessels. Most of the structural cardiovascular abnormalities are incidentally detected and may be symptomatic; however, a few are potentially significant and can trigger sudden death also.

\section{Financial support and sponsorship}

Nil.

\section{Conflicts of interest}

There are no conflicts of interest.

\section{REFERENCES}

1. Shirani J, Roberts WC. Solitary coronary ostium in the aorta in the absence of other major congenital cardiovascular anomalies. J Am Coll Cardiol 1993;21:137-43.

2. Njeim M, Nasr Y, Younes M, Song TK, Koenig GC, Nour K. Single coronary ostium in right coronary sinus: Previously unreported "one for all” configuration. Tex Heart Inst J 2014;41:601-2.

3. Rigatelli G, Rigatelli G. Congenital coronary artery anomalies in the adult: A new practical viewpoint. Clin Cardiol 2005;28:61-5.

4. Said SA, de Voogt WG, Bulut S, Han J, Polak P, Nijhuis RL, et al. Coronary artery disease in congenital single coronary artery in adults: A Dutch case series. World J Cardiol 2014;6:196-204.

5. Andreou AY, Kyprianou D, Eteocleous N, Theodorou S, Avraamides PC. A case of crossing coronary arteries. J Cardiovasc Med (Hagerstown) 2012;13:332-3. 